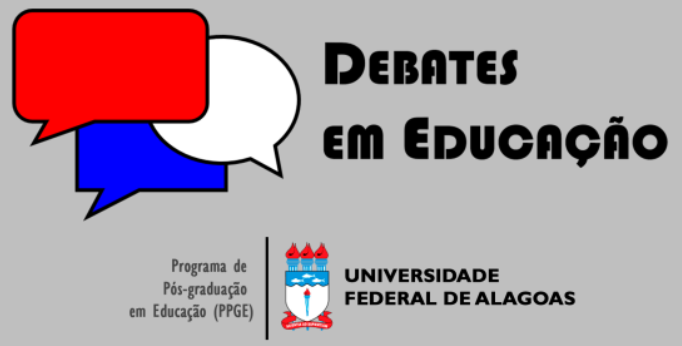

ISSN Eletrônico 2175-6600

Vol. I | | No. 23 | Jan./Abr. | 2019

Kássia Mota Sousa

9 in

Universidade Federal de Campina Grande (UFCG)

kassiamota@gmail.com

\section{RELATOS SOBRE A INFÂNCIA AFRODESCENDENTE NO SERTÃO NORDESTINO: REFERÊNCIAS PARA A PRODUÇÃO DA HISTÓRIA DA INFÂNCIA AFRODESCENDENTE}

\section{RESUMO}

Este artigo busca contribuir para a construção de referenciais para a compreensão da infância afrodescendente no interior do Nordeste Brasileiro (Ceará, Pernambuco e Alagoas) no período posterior à abolição da escravatura. Nosso esforço maior é no sentido de situar a infância afrodescendente na sociedade brasileira ao longo do tempo, refletindo sobre como estas crianças passaram do anonimato para a condição de cidadãs, com direitos e deveres aparentemente reconhecidos. Metodologicamente, elegemos a memória (de idosos negros sobre sua infância) e sua capacidade extraordinária de recriação de um passado que, de tão longínquo, parecia inexistente, mas, ao ser narrado, ressurge com força e vigor fazendo-nos perceber que a nossa infância, historicamente, sempre esteve à margem dos direitos humanos - civis, políticos, econômicos e culturais - que já pautavam o cotidiano do homem adulto, branco, civilizado do ocidente.

Palavras-chave: Infância. História. Populações afrodescendentes.

\section{REPORTS ON AFRODESCENDANT CHILDHOOD IN THE BACKLAND OF THE BRAZILIAN NORTHEAST: REFERENCES FOR THE PRODUCTION OF THE HISTORY OF AFRODESCENDANT CHILDHOOD}

\begin{abstract}
This article aims to contribute to the construction of references for the understanding of Afrodescendant childhood in the interior of the Brazilian Northeast (states of Ceará, Pernambuco and Alagoas) in the period after the abolition of slavery. Our effort is to place Afrodescendant childhood in Brazilian society over time. Reflecting on how these children went from anonymity to the condition of citizen, apparently with the rights and duties. Methodologically, we choose the memory (of the black elderly about their childhood) and their extraordinary ability to recreate a past that seemed so far away, but when it is narrated, it reappears with force and force, making us realize that our childhood, historically, has always been the margin of human rights civil, political, economic and cultural - that already guided the daily life of the adult, white, civilized man of the West.
\end{abstract}

Keywords: Childhood. History. Afrodescendant Populations.

Submetido em: $14 / 1 \mid / 2018$

Aceito em: 17/04/2019

Publicado em: 25/04/2019

d. http://dx.doi.org/10.28998/2 I75-6600.2019v| In23p6 I 2-624 


\section{INTRODUÇÃO}

Nosso interesse pela temática da infância negra remonta do nosso trabalho de mestrado (SOUSA, 20 I0) - "Entre a escola e a religião: desafios para crianças de Candomblé em Juazeiro do Norte" - quando buscamos compreender os processos escolares vivenciados pelas crianças negras. A pesquisa de mestrado objetivou compreender os significados e sentimentos que as crianças candomblecistas construíam sobre as suas experiências escolares.

No recorte histórico da pesquisa de mestrado (2008-20l0), as crianças negras, sujeitos da pesquisa, já eram compreendidas como sujeitos de direitos em um processo histórico que remonta à Idade Média, que introduziu concepções sobre família e infância - o que é reforçado por documentos nacionais e internacionais como o Estatuto da Criança e do Adolescente (1990); declarações, como a Declaração Universal dos Direitos da Criança (1959), dentre outros que, em termos legais, estabelecem as crianças como sujeitos de direitos. Contudo, a pesquisa concluiu que, devido ao racismo estrutural da sociedade brasileira, os reconhecidos direitos por educação e pela liberdade de credo das crianças ainda são postos em questão.

Ademais, foi no desenvolvimento da pesquisa de doutorado (20 I 5), na escrita de "Por onde andou nossa família: veredas e narrativas da história de famílias afrodescendentes no pós-abolição", que entramos em contato com os relatos sobre a infância negra em meados do século $X X$ e atentamos para o fato de que a infância é uma categoria histórica e que possui características distintas de acordo com os marcadores de sexo, território, raça e classe social.

Assim, nos aproximamos de um sentimento comum aos estudiosos de família e infância relatado por Del Priore (2012, p. 233). A autora afirma que

Para começar, a história sobre a criança feita no Brasil, assim como no resto do mundo, vem mostrando que existe uma enorme distância entre o mundo infantil descrito pelas organizações internacionais ou autoridades, e aquele no qual a criança encontra-se cotidianamente imersa.

Este sentimento invadiu nossa reflexão, principalmente quando nos deparamos com a produção sobre criança elaborada na Europa; então, formulamos as seguintes questões: Como conhecer a história da infância afrodescendente do nordeste brasileiro? É possível analisá-la a partir dos referenciais teóricos existentes?

Ao levantarmos o estado da arte, concluímos haver apenas uma meia dúzia de autores que discutem a história da infância negra e afrodescendente no Brasil. Dentre eles, Mary Del Priore, com o artigo Criança Negra no Brasil (20/2), nos apresenta um contexto que, apesar de muito diverso do encontrado na pesquisa, merece nosso conhecimento. Ela tenta responder questões referentes ao que chama de uma quase onipresença infantil. Tentando situar estas crianças na sociedade brasileira ao longo 
do tempo, refletindo sobre como teriam, estas crianças, passado do anonimato para a condição de cidadã, com direitos e deveres aparentemente reconhecidos, a autora propõe o exercício de "olhar para traz" na tentativa de ajudar a iluminar os caminhos que agora percorremos, entendendo melhor o porquê de certas escolhas feitas por nossa sociedade. (PRIORE, 20I2).

Quando retornamos ao período de colonização do Brasil, percebemos que até houve escolas para os indígenas, mas não para os negros, ainda que haja registros daqueles que aprendiam a ler e escrever: "Nos documentos, nem uma palavra sobre a educação de crianças negras ou de filhos de escravos, salvo a religiosa" (PRIORE, 2012, p.236). Assim, no século XIX, mesmo após a Proclamação da República, a velha ordem oligárquica, aristocrática, baseada no modelo casa-grande e senzala perpetua-se, e a única saída para os afrodescendentes ex-escravizados foi a sua transformação em elemento útil ao sistema, via a exploração de sua capacidade de trabalho, o processo de escolarização e de cidadania, via educação, Ihes fora amputado.

Solicitada desde 1824 e criada apenas em 1856 para atender as necessidades de uma população livre e vacinada, a escola pública proibia seus assentos às crianças escravizadas. Às pobres, provavelmente mulatas e negras, reservava espaço quando se tratavam daqueles que demonstravam acentuada distinção e capacidade, conforme (PRIORE, 20I2).

Ainda na construção do estado da arte sobre infância negra no Brasil, conforme Santos (2006), há uma infância afrodescendente na Bahia que salvaguarda e reelabora a sua cultura de matriz africana, principalmente ancorada nos terreiros de Candomblé. Mas o Brasil é um país de dimensões continentais, e um dos elementos que nos leva a pensar sobre a nossa infância é justamente esta ausência de salvaguarda no caso em estudo.

O fato é que no Ceará, Pernambuco e em Alagoas, territórios de vivência da infância do sujeito da pesquisa, o que observamos foi o desmonte histórico desta tradição alicerçada em várias estruturas da sociedade, seja nas relações estabelecidas em nosso território pelo catolicismo, tendo como figura central o Padre Cícero (no caso do Ceará); seja pelas estruturas econômicas, que fizeram vigorar relações de compadrio entre ex-escravistas e ex-escravizados no pós-abolição; ou ainda, devido aos desenlaces familiares, ocasionados pela dispersão dos membros pelo país em busca de trabalho, sobrevivência. $\bigcirc$ fato é que, em nossa família afrodescendente, o conceito ocidental de respeito, cuidado e atenção às crianças ainda está em processo.

Quando à abolição da escravidão, as crianças e adolescentes moradores de antigas senzalas continuaram a trabalhar nas fazendas de cana. Tinham a mesma idade de seus avós quando esses começaram: entre 7 e 14 anos, e era possível encontrá-los ainda cortando cana; assim, continuaram despossuídos das condições básicas de alimentação, moradia, saúde, educação. Como no passado distante, o trabalho doméstico entre as meninas perpetuava-se, constituindo-se, em um "outro" turno, 
suplementar ao que se realizava no campo. Como se não bastasse a ação de fatores econômicos interferiam na situação da criança, a ausência de uma política do Estado voltada para a formação escolar da criança pobre e desvalida, o que só acentuava seu miserabilismo. Ora, ao longo de todo esse período, a República seguiu empurrando estas crianças para fora da escola, na direção do trabalho na lavoura, alegando que ela era "o melhor imigrante".

Durante a pesquisa do mestrado, estudando as crianças do século $X X \mathrm{I}$, compreendemos que ainda hoje são atuais as denuncias sobre os embates e conflitos do cotidiano de crianças afrodescendentes em oposição ao que reza o Estatuto da Criança e Adolescente (ECA). O que percebemos é que nossa infância sempre esteve à margem e luta para alcançar a emancipação e os direitos humanos, civis, políticos, econômicos e culturais que já pautam o cotidiano do homem adulto, branco, civilizado do ocidente.

Partimos para esta reflexão, que está num momento inicial, ensaístico, afırmando que o conceito de infância ocidental pós-Idade Média, desconsiderou e desconhece as experiências da infância da população afrodescendente brasileira. Neste sentido, é que nos voltamos para infância afrodescendente no interior do Nordeste Brasileiro, nos estados de Pernambuco, Ceará e Alagoas. Os relatos analisados no texto aludem as experiências vivenciadas na infância por uma mulher, negra, nascida em 1932, que viveu sua infância em trânsito, migrando com sua família pelo sertão nordestino.

\section{SOBRE O SUJEITO DA PESQUISA}

Para esta reflexão trazemos um recorte do texto de doutorado onde ouvimos atentamente as memórias acerca da infância de uma mulher negra, de 86 anos de idade, minha tia-avó, M. N. S. Quando eu a expliquei qual era o projeto - escrever a história de nossa família, ela sorriu. Emocionada, perguntou "pra quê?", mas nunca se curvou de nenhuma pergunta; muitas vezes pediu desculpa ao dizer "Não lembro".

A escolha metodológica pela história da família como sujeito de pesquisa foi também uma escolha teórica. A reflexão sobre nossa ascendência, sobre nossa identidade, é um caminho oposto ao colocado pela sociedade racista, o que dificulta a realização da tarefa científica para nós negros, conforme Milton Santos (1983): "para o psiquismo em ascensão, que vive o impasse consciente do racismo, o importante não é saber o que pode vir a dar-lhe prazer, mas o que é desejável pelo branco" (p.7).

Nesta perspectiva, a metodologia afrodescendente nos amparou conceitual e metodologicamente a menoscabar a questão do estranhamento do pesquisador com o seu objeto/sujeito investigado, exaltando a importância dos escritos sobre a população negra, terem autoria negra. Assim, conforme Giovana Xavier (2017), é recomendável que a produção acadêmica substitua mulheres negras como objetos de estudo por mulheres negras contando a sua própria história; ou seja, sujeitas da sua produção. 
Irmã de meu avô, M. N. S. fez com ele a viagem de União dos Palmares (Alagoas) para o Ceará.

E, apesar de desejosa em colaborar com nossa pesquisa, apresentava lapsos de memórias que desafiavam a pesquisadora ávida por linearidade. Seus relatos de infância remontam às vivências no estado de Pernambuco, Alagoas e Ceará, rememorando a infância, conta que a viuvez de sua mãe, minha bisavó, os trouxe para o Cariri Cearense; primeiro para a cidade do Crato e depois para Juazeiro do Norte. Neste momento sua memória torna-se mais vívida e ela descreve a desumanização do trabalho doméstico a que fora submetida ainda na infância.

\section{INFÂNCIAS NEGRAS PELO SERTÃo}

Ao analisar a fala da Tia M. N. S., percebemos o quão presente ainda era a concepção de infância forjada pelo sistema escravista latifundiário que se perpetuou e ecoou dentro da família afrodescendente, fundamentando os processos de violência, abandono e conflito vivenciados e relatados pelo sujeito da pesquisa, e também por outros membros da sua família negra que expressaram experiências de "invisibilidade e anonimato" durante a infância. Por exemplo, nos relatos do sobrinho de N.M.S., ele descreveu os trabalhos domésticos que foi obrigado a realizar, auxiliando sua mãe a prover a família, já que seu pai se separou da sua mãe, desde muito cedo, indo viver do corte da cana de açúcar pelo sertão afora. Histórias semelhantes ocorridas entre o fim do século XIX e início do século $X X$ confirmam nossa tese de que a infância afrodescendente fora marcada pela exploração do sujeito pelo sistema latifundiário ou pela negação de sua humanidade quando inútil a este sistema. Mesmo após o processo abolicionista e dentro das famílias afrodescendentes, este conceito de infância foi perpetuado.

Período colonial brasileiro, faz-se presente também outra ideia de infância, agora para os filhos de escravos. Além de destituída de humanidade, incivilizada, era também um problema, já que teria que ser alimentada e formada em um ofício, gerando prejuízos para o sistema escravistalatifundiário. Os brancos-europeus interessavam-se pelos escravos adultos, por gerarem lucro imediato, a partir da mão-de-obra já pronta para a exploração do trabalho (SANTOS, 2006, p.36).

Há importantes pesquisas que tratam da vida privada das crianças negras durante o período escravagista. Contudo, durante o período histórico posterior, o período pós-abolição, não encontramos relatos sobre como viviam os pequenos negros livres do Brasil. Neste panorama nossa pesquisa traz como questão a compreensão sobre a infância afrodescendente no período pós-abolição.

Quanto ao processo de escolarização das crianças, Ariès ( 1978) diz que, a partir do fim do século XVII, houve uma mudança considerável quando a escola substituiu a aprendizagem como meio de educação. Isso quer dizer que a criança deixou de ser misturada entre os adultos e de aprender a vida diretamente, através do contato com eles. A despeito das muitas reticências e retardamentos, a criança foi 
separada dos adultos e mantida à distância em uma espécie de quarentena antes de ser solta no mundo. Essa quarentena foi a escola, o colégio. Começou, então, um longo processo de enclausuramento das crianças que se estenderia até nossos dias, e ao qual se dá o nome de escolarização. Os achados de pesquisa em nossa família nos levam a propor que a escolarização das crianças negras só acontecerá a partir da geração nascida em meados do século $X X$ : meu pai, seus irmãos e primos são os primeiros negros de nossa família a frequentar a escola.

E ainda segundo Ariès ( 1978), o processo de escolarização das crianças é resultado de uma outra mudança, quando a família se tornou o lugar de uma afeição necessária entre os cônjuges e entre pais e filhos, algo que ela não era antes. Essa afeição se exprimiu, sobretudo, através da importância que se passou a atribuir à educação. $\bigcirc$ que Ariès (1978) relata ocorrer no século XIX e XX tratava-se de um sentimento inteiramente novo: os pais se interessavam pelos estudos de seus filhos e os acompanhavam com uma solicitude habitual nos séculos $X I X$ e $X X$, algo que só vimos ocorrer em nossa geração.

Analisando a tese de Ariès e comparando-a aos achados sobre infância afrodescendente, concluímos que estes dois processos citados pelo autor, afeição familiar e escolarização, só ocorrerão tardiamente nas famílias afrodescendentes. A fala de N.M.S. denota que a afeição tem pouco espaço no núcleo familiar; nas espaças e confusas lembranças há silêncios e silenciamento, e não se encontra registros mnemônicos de demonstrações de afeto familiar ou preocupação por sua escolarização.

Em oposição à esta experiência, Ariès ( 1978) afirma que a família começa então a se organizar em torno da criança e a lhe dar uma tal importância; que a criança saiu de seu antigo anonimato; que se tornou impossível perdê-la ou substituí-la sem uma enorme dor; que ela não pôde mais ser reproduzida muitas vezes, e que se tornou necessário limitar seu número para melhor cuidar dela. $\bigcirc$ que não percebemos na família afrodescendente caririense, o relato de Tia N.M.S. nos informa que o núcleo familiar não tinha toda esta importância:

Minha filha, quando eu tinha 4 a 5 anos, 6 ano eu sufria, eu sufria que nessa idade ai eu não tava com minha mãe, eu tava com minha tia madrinha, porque minha tia-madrinha nunca teve, (irmã da minha mãe) nunca teve filho, aí foi na casa de minha mãe e me pediu, pra minha mãe dá eu pra ela, pra pra eu pegar pressão no fogo pra acender o cachimbo que era só o que eu podia fazer né. (N.M.S., 20I3).

No momento deste relato, entre 4 e 5 anos de idade, a ainda menina N.M.S. é dada para criação (adoção) à uma tia, para auxiliar nos trabalhos domésticos. Ela relata seu cotidiano de trabalhos domésticos, castigos e abusos de violência:

Ai minha filha qualquer erro que eu fizesse, um dia vou dizer um dos erros que tô lembrado aqui, eu, ela foi pra roça mais meu padim, marido dela, e disse: - N.M.S. Ocê bota fogo, bota lenha no fogo, bota lenha no fogo pra quando eu chegar é pro feijão tá cozinhado. (N.M.S., 20I3, grifo de autoria da pesquisadora). 
Ela conta que era tão pequena que precisava subir em um banco para alimentar o fogão a lenha e, naquele dia, colocou tanta lenha no fogão que subiram grandes labaredas de fogo; a panela ficou preta de tantas chamas e fumaça. Quando sua tia chegou, foi tomada pela raiva. Ela relembra a fala da tia-madrinha: "Ocê botou lenha de mais nessa panela. O feijão tá quase queimado. Você vai levar umas lapada pra ocê aprender fazer as coisa" (N.M.S., 2013). Durante nossas conversas, ela relatou vários momentos de fuga, com medo das agressões físicas que vivenciava. Sempre que advertida fugia para as matas: "Minha fia, eu apanhava tanto que quando ela dizia "Ocê vai levar umas lapada", eu já pegava o caminho e sai correndo pra dentro das matas." (N.M.S., 2013).

Na casa de sua tia-madrinha ela fazia os trabalhos domésticos como lavar a louça, cozinhar, varrer, alimentar os animais de criação. Apesar de sua pouca idade, 5 anos, na sua rotina não havia espaços para brincadeiras e escola; sua rotina era de trabalhos domésticos e agressões físicas. Em seus relatos não se percebe afeto, felicidade e o conceito de família e infância é totalmente diferente do que temos hoje.

Seus relatos denotam uma infância de curta duração; assemelham-se às descrições da infância na sociedade tradicional onde, segundo Ariès (1978), a infância era reduzida ao seu período mais frágil, enquanto o filhote do homem ainda não conseguia bastar-se; a criança, então, mal adquiria alguma desenvoltura física e era logo misturada aos adultos, partilhando de seus trabalhos e jogos. De criança pequena, ela se transformava imediatamente em homem jovem sem passar pelas etapas da juventude que talvez fossem praticadas antes da Idade Média e que se tornaram aspectos essenciais das sociedades evoluídas de hoje:

Outra vez eu tinha que lavar os prato no rio, ia lavar no rio. Ai lavando os prato né, mas sem eu querer caiu uma colher dentro d'agua. $O$ rio levou, a água suja, eu num tava nem vendo a colher se eu podia pegar, nada, eu via que a água tava baldeada suja, eu cheguei em casa e falei pra ela, madrinha caiu uma colher dentro do rio. Ocê jogou a colher e a água levou a colher, sem vergonhe! Pêra que ocê vai apanhar que é pra aprender fazer as coisa, e tome cipó de fogo e tome cipó de fogo, tome cipó de fogo. Outra vez, dava tanto que eu ficava queimada, ficava toda queimada, aqueles vinco preto, eu já sou preto e os vinco ficava mais preto ainda, a pele voando e o couro preto da pancada do cipó de fogo [...] E outra vez, a cabra, a cabra eu ia amarrar as cabra, já tinha de 5 pra 6 ano já ai, eu ia amarrar as cabra tinha que amarrar três cabra, longe, longe, longe, nera pertinho não. Mas, uma eu amarrei num lugar que não tinha um pezinho de pau pra eu amarra num sabe, então peguei um moi de capim e amarrei, amarrei ai vim embora pra casa. Ai quando foi assim pelas 4 horas, 4 horas e meia, esse horário assim o sol já tava espalhado lá onde a gente morova, chegou um homi, dona a sua cabra tá comendo a minha roça, comendo as mandioca. $\bigcirc$ quê? Ai foi já lá, meu padim tava em casa foi também, e eu também fui atrás. Aí chegou lá meu padim puxou a cabra de dentro da roça dele, tava comendo só as folha da mandioca, mas mesmo assim, tivesse comendo as batata, mas tava comendo as folha, mas mesmo assim foi preciso eu apanhar, né? Ai quando ela pegou a cabra e puxou pra fora da roça do homi, no meio do caminho assim na beira do caminho que ia lá pra casa né, ai eu corri, ele puxou a cabra pra dentro da roça, eu tava meio perto pra ver a cabra, ai eu corri, quando eu corri, ele correu atrás de mim e me pegou, ele correu e me pegou e me derrubou no chão, derrubou no chão e saiu puxando, assim puxando por uma perna por cima dos caco que tinha, tinha derrubado um engenho veio que tinha assim, tinha derrubado um engenho e tinha um bucado de caco de tijolo, caco de telha pedaço de pau tudo no chão, e quando me puxava tinha que passar por cima (...) e chegou em casa, tome lapada, tome cipó de fogo, tome cipó de fogo, tome cipó de fogo e eu aiaiaiaiaiaiai mas mesmo assim, tinha tinha que engoli. (N.M.S., 20I3). 
Tia N.M.S. descreveu um episódio em que dormiu uma noite na mata, enquanto fugia de sua tiamadrinha. Em seus relatos há uma confusão sobre onde isto ocorrera, talvez pela quantidade de migrações que vivera, talvez pela pouca idade na época. Ora ela se reportava ao episódio como tendo ocorrido em Alagoas, ora em Pernambuco. Mais o fato é que aos 5 anos de idade, a garota dormira só, em mata fechada. Ela descreve que,

\begin{abstract}
Num tinha medo de nada, Deus é um tão bom, pai que nunca botou, num botou uma cobra pra passar na frente de mim, pra eu chegar perto de mim, nosso poderoso pai, viu! Só ele pra nos fazer tudo de bom mesmo, né? Ai quando chegou lá adiante, num lá que horas da noite tudo escuro, ai eu vou ficar aqui em cima dessas folha, se deitei em cima das folha e fique e as muriçoca te come, te come, te come e eu tangendo, tangendo, tangendo e assim passei a noite. Ai quando chegou, era assim, pro dia amanhecer, o dia ta clareando, ta clareando fora da mata, já tava bem mais claro, mas dentro da mata ainda tava um pouco escuro não dava pra eu ver bem as coisas não. Mas daqui a pouco, lá vem umas pisada por dentro das folhas seca sabe, assim por trás de mim, lá vem uma pisada como se fosse uma pessoa andando por cima das folhas seca, tcha tcha tcha, eu, eita é a madinha, eu só tinha medo dela, podia ser o bicho que fosse não me fazia medo. Eu só tinha medo, eita é madinha, mas aí não me mexi do canto não, fiquei, fiquei ali no canto né. Ai minha filha o bicho arrodeou por trás de mim e vinha assim por as minhas costas, eu deitada aqui e o bicho veio assim pelas minhas costas, eu com as costas pro lado dele, ele veio arrodeou assim pela minha cabeça, ai ficou assim, cara com cara comigo, cara com cara, aquele bicho da carona uma carona, nera bichinho cara pequena não, fucinho pequeno não, fucinzão aquele fucinzão, sabe o que ele fez? Ele encostou a venta dele com a minha, acho pra ver se eu tava viva. Se eu tivesse morta, ele um bucado pronto pra ele, mas quando ele encostou a venta na minha e sentiu que eu tava respirando, ai Nosso Senhor, Nosso Poderoso Pai somente ele pra fazer tudo de bom né? Ai quando ele sentiu que eu tava respirando, ele virou assim pra trás e ilhé ilhé e saiu correndo. Um lobo, um lobo, um bichão um lobo, nesse tempo tinha lobo, né! (N.M.S., 2013).
\end{abstract}

Tia N.M.S. relata que chegando em Juazeiro do Norte, Ceará, cada irmão foi trabalhar numa casa diferente e todos(as) como empregados(as) domésticos(as), homens e mulheres realizando as funções de cozinheiro(a), faxineiro(a), jardineiro(a). As difíceis condições de trabalho vivenciadas na juventude deixaram marcas profundas de subalternidade em sua subjetividade.

Hoje, idosa e viúva, tia N.M.S. se refere a si como ser utilitário e diz não entender como "Nosso Senhor Jesus" ainda não a "levou" se ela já não pode servir a mais ninguém. Quando adentramos sua história de vida, compreendemos que, mesmo que não haja memória de antepassados cativos, já que a tia N.M.S. nasceu em União dos Palmares, Alagoas, um importante quilombo, e ainda que nunca tenha vivenciado a escravidão, ela experimentou ao longo de sua vida um processo de desumanização e de coisificação. Foi vítima, juntamente com nossa família, de um arcabouço ideológico onde a função social perpetrada para o negro era o "servir" indistintamente aos brancos.

E quando situamos nossa narradora no tempo, suas experiências e narrativas de vida desafiam a história política e social escrita sobre o Brasil do século XX. Os relatos e experiências de trabalho da família Sousa desafiam-nos, pois são anacrônicos se comparados aos relatos desenvolvimentistas do Brasil no final do século $X X$. Suas condições de trabalho, predominantemente domésticos, são similares às condições de trabalho do cativeiro. 
Três, quatro anos era o que eu podia fazer, num sabia fazer nada. Ai minha mãe tinha dez filho, né? Ai disse vai N.M.S. arruma suas coisinhas e vai com ma com sua madrinha pra casa dela, a gente morava longe nera pertinho não, agente morava, nera, em Pernambuco mais muito distante muito distante, ai mandaram N.M.S. ir com você ela é sua afilhada e ocê pode dizer que vai ter ela como ser sua filha. Mas menina o que eu sofri nesse tempo de criança até os seis ano, até seis ano. Dos quatro ano, dos três ano até os seis ano na mão dela, o que eu sufri é de você nem acreditar. (N.M.S., 2013, grifo de autoria da pesquisadora).

Na ausência de produção sobre o período histórico estudado, pós-abolição, nos reportamos aos estudos que descrevem a família "escrava" no Cariri Cearense e, para compreender esta organização social na qual estava inserida a minha família paterna, é importante entender que esta é uma família de migrantes, vindo de Alagoas, conforme a certidão de casamento do meu avô. Ele nasceu em União dos Palmares e, com eles, certamente migraram também compreensões acerca das organizações sociais que podem ser de ajuste ou oposição ao que já estava estabelecido na região do Cariri Cearense.

Cortez (2008) explica-nos que as famílias "escravas" são responsáveis por grande parte da organização social dos cativos; é a família "escrava" que possibilitará, segundo ela, a integração na sociedade para além da senzala e que houvera uma incompreensão desta organização, já que durante as primeiras décadas do século $X X$, os estudos em torno da família "escrava" tinham como base duas instâncias principais: a não existência ou a compreensão dessas relações como promíscuas e mais ainda: responsáveis pela ilegitimidade de muitos "mulatinhos".

A fala da Tia N.M.S. sobre a sua infância nos fez refletir sobre a produção acadêmica acerca da infância afrodescendente no pós-abolição. O que nós sabemos sobre as crianças afrodescendentes no pósabolição? Afinal, o que sabemos sobre as crianças afrodescendentes? Mary Del Priore (20I2) anuncia as questões para as quais devemos voltar nosso olhar de historiadores para entendermos as atuais relações sociais. Ela diz que a "quase" onipresença infantil nos obriga, pois, a entender algumas questões. Dentre elas:

Terá sido sempre assim? O lugar da criança negra na sociedade brasileira terá sido sempre o mesmo? Como terá ela passado do anonimato para a condição de cidadã, com direitos e deveres aparentemente reconhecidos? Numa sociedade desigual e vincada por transformações culturais, teremos, ao longo dos tempos, recepcionado nossas crianças da mesma forma? Sempre choramos, do mesmo jeito, a sua perda? Que marcas trazem as crianças de hoje, daquelas que as antecederam no passado? Mas há, também, questões mais contundentes tais como, por que somos insensiveis as crianças negras que mendigam nos sinais? Por que as altas taxas de mortalidade infantil, agora, começando a decrescer, pouco nos interessam? Essas respostas, entre tantas outras, só a história pode dar. Não será a primeira vez que o saudável exercicio de "olhar para traz" irá ajudar a iluminar os caminhos que agora percorremos, entendendo melhor o porquê de certas escolhas feitas por nossa sociedade. (DEL PRIORE, 20I2, p. 233).

Percebemos que o estudo das representações ou das práticas infantis é considerado tão importante que a historiografia internacional já acumulou consideráveis informações sobre a criança e seu passado. $\mathrm{Na}$ Europa, por exemplo, há trinta anos, a demografia histórica ajudava a detectar a expectativa de vida, o papel da criança nas estruturas familiares, os números do abandono infantil ou da contracepção. Os 
trabalhos de Ariès dão início a este resgate histórico na Europa; neles ele apresenta duas teses que revolucionariam o tema. Para o autor, teriam sido a escolarização e a vida privada propulsores de grandes mudanças.

Segundo Ariès, a escolarização, iniciada na Europa no século XVI e levada a cabo por educadores e padres, católicos e protestantes, provocou uma metamorfose na formação moral e espiritual da criança, em oposição à educação medieval feita apenas pelo aprendizado de técnicas e saberes tradicionais, na maioria das vezes, ensinados pelos adultos da comunidade. A Idade Moderna passa a preparar, nas escolas, o futuro adulto. Ou seja, a criança, esse potencial motor da História, é vista como o adulto em gestação. Paralelamente à essa mudança, a família sofria, também, uma profunda transformação com a emergência da vida privada e uma grande valorização do foro íntimo. A chegada destas duas novidades teria acelerado, no entender de Ariès, a supervalorização da criança. Apesar de todas as críticas que essas teses receberam, sobretudo quanto à percepção de certo "evolucionismo" na condição histórica da criança - essa, na Idade Média, não significaria muito para seus pais, passando a condição de "reizinho do lar" com a evolução da sociedade burguesa, as teses nos instigam a procurar nossas próprias respostas acerca da infância no Brasil. E por quê?

As teses de Ariès nos instigam a procurar novas respostas, respostas à brasileira, porque entre nós, a emergência da escolarização e da vida privada, os dois motivos elencados por ele como responsáveis pela introdução do pensamento moderno sobre infância, se dão tardiamente. E no caso da população afrodescendente a defesa da educação pública, gratuita e de qualidade é recente e ainda atual, pois o processo de escolarização das crianças brasileiras ocorrido desde a colonização não tinha como foco a criança afrodescendente.

Desde o início da colonização, as escolas jesuítas eram poucas e, sobretudo, para poucos. O ensino público só foi instalado, e ainda assim mesmo de forma precária, durante o governo do Marquês de Pombal, na segunda metade do século XVIII (DEL PRIORE, 20I2).

Já no século XIX, a opção para os filhos dos pobres não era a educação, mas a sua transformação em cidadãos úteis e produtivos na lavoura, enquanto os filhos de uma pequena elite eram ensinados por professores particulares. $\bigcirc$ que encontramos após a abolição da escravidão são as crianças e adolescentes moradores de antigas senzalas que continuaram a trabalhar nas fazendas.

Nos relatos de N.M.S., a escolarização durante a infância aparece de forma muita rarefeita e conjunta à situação de trabalho, demonstrando um processo de profissionalização precoce. Quando abordada sobre escola, ela diz que: "Ai eu ia estudar. A dona, minha patroa, vai querer não! Vai pra escola? Não! Eu vou, eu vou. Aí, eu ia. Até que aprendi mais ou menos, mas teve delas (irmãs), que num sabe nem o que é um zero" (N.M.S., 2013). 
E a partir deste relato podemos traçar uma linha histórica que nos leva a empreender que até hoje, de uma forma geral, continuam, as crianças afrodescendentes, despossuídas das condições básicas de alimentação, moradia, saúde, educação e garantias trabalhistas. A partir da fala da Tia N.M.S., veremos que o trabalho doméstico entre as meninas também é uma constante. Como se não bastasse a ação de fatores econômicos a interferir na situação da criança, a ausência de uma política do Estado voltada para a formação escolar da criança afrodescendente e pobre só acentuou seu miserabilismo e invisibilismo.

Ela relata que na chegada em Juazeiro de Norte, Ceará, sua mãe orientou todos os seus filhos a buscar trabalhos domésticos. Homens e mulheres, na verdade adolescentes, iniciaram a vida profissional através do trabalho doméstico. Ela própria somente conheceu o trabalho doméstico como forma de obtenção de renda. "O José, João (irmãos de N.M.S.) tudo procuraram emprego, tudo procuraram emprego. Faxineiro nas casas, empregado de jardim pra ficar aguando jardim, limpando, plantando, virando, mexendo, né?" (N.M.S., 2013, grifos de autoria da pesquisadora). Aqueles que não se ocuparam de tarefas domésticas foram vivenciar trabalhos pesados e menos valorizados.

Os outros era, o Manoel era pra? Num se o que motor, comotor fazer num cê o que, nem me lembro mais o que era. Motor, trabalhando no negócio lá que tinha que movimentar com o motor, num to mais lembrado o que era não. E o João tinha que trabalhar com o jumento, traficando com carga, de jumento, montava no jumento (...) é, colocava na carroça e levava o que fosse preciso, levava num sei pra onde, num sei pra onde, pro Crato, num sei pra onde que fosse... (N.M.S., 2013).

Como se vê, a pobreza e a falta de escolarização da criança negra brasileira ao longo de sua história tornam as teses europeias inadequadas para nossas terras. A divisão da sociedade, velha divisão dos tempos da escravidão, entre os que possuem e os que nada têm, só fizeram agravar a situação dos nossos pequenos negros. A escolarização foi projeto tardio para os afrobrasileiros.

Tia N.M.S. narra que, ao chegar no Cariri Cearense, residiram na zona rural e só depois migraram para Juazeiro, zona urbana, onde estavam concentradas as escolas da época. De qualquer forma, o projeto familiar não contemplava a escolarização. Em nossa experiência familiar somos apenas a segunda geração a desafiar o estigma do analfabetismo, e mesmo que nosso pai e tios tenham frequentado a escola, ela não possibilitou a transformação social de suas vidas. Possuindo poucos anos de escolarização, nossos pais não conseguiram um projeto de vida diferente do vivenciado pelos seus pais e avós.

\section{CONSIDERAÇÕES FINAIS}

Este trabalho dá inicio à uma reflexão acerca das questões relativas às concepções acerca da infância, especificamente da infância afrodescendente no Brasil pós-colonial. Na tentativa de conhecer a história da infância afrodescendente nordestina, buscamos nas experiências, na história oral, na memória, 
metodologias capazes de lançar luzes sobre esta infância, já que o estado da arte demonstra a insuficiente produção teórica sobre crianças negras no Brasil.

As dificuldades com relação à escolarização, expressa nos relatos, é responsável também por ampliar as dificuldades de definição do lugar da criança negra no meio social, já que os relatos denunciam que a condição de cativo, para as crianças, não teve fim imediato com a abolição da escravatura.

Assim, nossas reflexões finais afirmam a importância de resgatarmos e escrevermos as nossas histórias pessoais, na perspectiva de construção da História da População Afrobrasileira. Dentre nossas conclusões acerca do pós-abolição está a certeza de que há uma pluralidade enorme de formas de existência da população negra. Nossa história não deve ser generalizada - sua apresentação aqui tem outro sentido, onde desejamos contar o que vivemos, uma história que nos é particular e que revela a possibilidade de outras histórias particulares que, ao serem reveladas, em conjunto, comporão a história da população Afrobrasileira.

É necessário denunciar que a liberdade, como ficou explícito, não significou uma ruptura com a desqualificação do passado em cativeiro. A equiparação civil que, em tese, deveria dar base ao tratamento igual aos indivíduos, serviu para reafirmar seus antigos "lugares sociais", no caso específico das crianças negras, o não lugar.

Evidencia-se, então, como o território da liberdade ancorada ao mito da democracia racial é pantanoso: há mais de 150 anos após a abolição vivemos ainda um estágio de quase cidadania.

E afirmamos, inclusive, que a abolição foi circunstanciada à medida que nos livramos das pesadas correntes de ferro fundido, mas continuamos presos a um imaginário social velho, mas não caduco, assentado na velha ordem social e cristalizado pela ideologia racista. Sob este imaginário toda a população negra sempre será descendente das agruras da escravidão. Ao escrevermos esta história incidimos sobre outros problemas enfrentados pela população afrodescendente, como a superação do estigma da escravidão e o fardo do passado em cativeiro.

\section{REFERÊNCIAS}

ARIÈS, P. História social da infância e da família. Tradução: D. Flaksman. Rio de Janeiro: LCT, 1978.

CORTEZ, Ana Sara Ribeiro Parente. Cabras, caboclos, negros e mulatos: a família escrava no Cariri cearense (I 850 - 1884). 2008. 245 f. Dissertação (Mestrado em História) - Universidade Federal do Ceará, Departamento de História, Programa de Pós-Graduação em História Social, Fortaleza - CE, 2008.

DEL PRIORI, M. A criança negra no Brasil. In JACÓ-VILELA, AM., and SATO, L., orgs. Diálogosisépẹiem psicologia social [online]. Rio de Janeiro: Centro Edelstein de Pesquisas Sociais, 2012. p. 232-is 253. Available from SciELO Books <http://books.scielo.org > . 
SANTOS, Ana Katia Alves. Infância Afrodescendente: Epistemologia Crítica do Ensino Fundamental. Salvador: EDUFBA, 2006.

SOUSA, Kássia Mota. Entre a escola e a religião: Desafios para as crianças de Candomblé em Juazeiro do Norte. 20 I0. Dissertação (Mestrado em Educação) - Universidade Federal do Ceará, Programa de Pósgraduação em Educação Brasileira, Fortaleza - CE, 2010.

SOUSA, Kássia Mota. Por onde andou nossa Família: Veredas e Narrativas da História de Famílias Afrodescendentes no Pós-Abolição. 20 I 5. Tese (Doutorado em Educação). - Universidade Federal do Ceará, Programa de Pós-graduação em Educação Brasileira, Fortaleza - CE, 2015.

N.M.S. Entrevista realizada em 14 de agosto de 2013 .

XAVIER, Giovana (Org.). Catálogo Intelectuais Negras Visíveis. Rio de Janeiro: Malê, 2017. 